ISSN $0819-2642$

ISBN 9780734040169

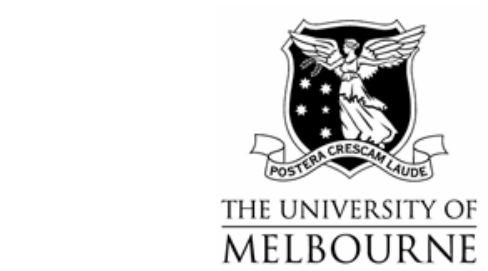

THE UNIVERSITY OF MELBOURNE

DEPARTMENT OF ECONOMICS

RESEARCH PAPER NUMBER 1050

July 2008

\title{
A Systematic Analysis of Quality of Teaching Surveys
}

by

Martin Davies, Joe Hirschberg, Jenny Lye \& Carol Johnston

Department of Economics

The University of Melbourne

Melbourne Victoria 3010

Australia. 


\title{
A Systematic Analysis of Quality of Teaching Surveys
}

\author{
Martin Davies \\ Teaching and Learning Unit, \\ Faculty of Economics and Commerce, University of Melbourne \\ Joe Hirschberg \\ Department of Economics, University of Melbourne \\ Jenny Lye \\ Department of Economics, University of Melbourne \\ Carol Johnston
}

Faculty of Economics and Commerce, University of Melbourne ${ }^{1}$

July, 2008

\begin{abstract}
All tertiary institutions in Australia use the same Course Evaluation Questionnaire (CEQ) however for the internal evaluation of teaching they use their own surveys. This paper performs an analysis of the internal Quality of Teaching Surveys (QTS) used in Australian Universities. We classify the questions within the QTS surveys. This classification is used to explore how different universities' surveys are similar to each other. We find that some universities use a QTS that is quite distinct from other universities. We also investigate whether there is a particular pattern to the types of questions used in the surveys. We find that there are some question types that are employed widely in a typical survey and others that are

\footnotetext{
${ }^{1}$ This research was conducted under a Learning and Teaching Performance Fund grant from the University of Melbourne. Address all correspondence to Joe Hirschberg, Department of Economics, University of Melbourne, Vic., 3010, j.hirschberg@unimelb.edu.au
} 
not. This analysis can be used by universities to determine how their surveys compare to their peer institutions and other institutions across Australia.

\section{Introduction}

Recent trends in higher education have indicated a greater emphasis on quantitative measures of institutional performance. One of the important developments in Australia has been the incorporation of data from the Course Experience Questionnaire (CEQ) (Ramsden, 1991a, 1991b; Ramsden \& Entwistle, 1981) into national benchmarking and funding decisions. Since 1993, the CEQ has been conducted annually across the graduates of all Universities in Australia by the Graduate Careers Council of Australia. Similar national quality assurance surveys are used in the UK, NZ and in many states of the US (Barrie and Ginns 2007).

Despite the role it has assumed in the evaluation of higher education quality, the CEQ has limitations. The lagging and aggregate nature of the data make it difficult for institutions to use CEQ data alone in their internal continuous and locally-responsive quality improvement activities. The key aim of the CEQ is to measure student perceptions of their courses of study following graduation and to assess differences between academic units in terms of those perceptions (Lizzio, Wilson, \& Simons, 2002; Ramsden, 1991b). The format of the questions in the CEQ is focussed on student experiences, not on the characteristics of teachers or the curriculum (Ramsden 2003). The CEQ is not designed to measure student perceptions of individual lecturers or units of study.

In order to gain an understanding of student perceptions of individual lecturers or units of study Australian higher education institutions have developed institution-specific instruments and surveys to provide context-relevant data and "... to provide the evidence base from which to effect improvements in their performance on ... national measures" (Barrie and 
Ginns 2007, pg. 278). ${ }^{2}$ These Quality of Teaching surveys (QTS), with names such as QOTs, SETs, LETs, TEVALs, have grown to play an important role in quality assurance in Australian higher education. In 2003 the Australian Government announced the Learning and Teaching Performance fund (LTPF) to reward higher education providers that best demonstrate excellence in teaching and learning for undergraduate domestic students. To be eligible for funding the government requires institutions to provide evidence that the institution QOT surveys informs probation and promotion decisions for academic positions (DEST 2006).

In this study we perform a systematic analysis of QTS applied in tertiary institutions. By examining the nature of the surveys employed in Australian tertiary institutions we can begin to understand how different institutions monitor the quality of their instruction. In Section 2 we describe the data collection process. Section 3 provides an analysis of how the surveys differ by institutions and groups of institutions. Section 4 contains the results of an analysis of the frequency of use of questions by type. Conclusions are provided in Section 5.

\section{The Data}

We conducted an email survey of all 39 universities Australian Universities (37 public and 2 private) over the period May-June 2006. In addition, we posted notices seeking information in the Higher Education Research and Development Society of Australasia (HERDSA), TeachEval and Unilearn. TeachEval is an email list of evaluation administrators. Unilearn lists academic learning advisors nation-wide. There was only one university that, at the time, did not conduct a QTS. A further 2 Universities did not respond but they had made sufficient information available on their website. It is a requirement of all institutions requesting funding from the Australian government's LTPF that information about teaching evaluation procedures, and data derived from surveys, is publically available on university websites (DEST 2006). The data obtained from email responses and websites can therefore be

\footnotetext{
${ }^{2}$ A unit of study is defined as a subject attracting credit points toward an award programme such as a degree.
} 
considered accurate and reliable. In order to ensure that the survey data we had obtained through email and web site data was an accurate and reliable as possible we established an online database called "Evaluation Central" in which institutions can themselves confirm the accuracy of the data as well as the way in which items in the survey for their particular institution have been classified according to the classification system of question types that we devised $^{3}$.

\subsection{The Institutional Practices}

We surveyed institutions to obtain information on: the name of their survey; whether there was a separate survey for units of study and lecturers; whether evaluation was conducted online, in paper-based form or both; the period of data collection; whether the QTS was compulsory, effectively mandatory or optional ${ }^{4}$; whether the data was available for research purposes; the name of Unit responsible for collecting the data; the number of core questions in the survey and whether there were open response questions.

\subsection{The Questions}

While it is generally considered that students' perceptions of institutional quality are multidimensional in nature there is less agreement as to the number and nature of the dimensions (Jackson et al. 1999). We classified the questions within the surveys according to the type of information that was sought by each institution. We devised a schema which clustered similar questions together by developing our own classification of 18 question "types" (QTs). For example, a number of institutions ask for responses to a question that is similar or identical to: "This subject is well taught" (Question 2 in the University of Melbourne survey). In our schema, all questions of this nature were clustered under the question type: “Overall Teaching Quality". Other questions were similarly grouped together under question types capturing the perceived intent of the question.

\footnotetext{
${ }^{3}$ The complete list of the data used in this study are available in the appendix to Davies et al. (2007).

4 "Compulsory" was defined as being a systematic, institution-wide practice required by the university and conducted on a regular, or semi-regular basis for all teaching staff. "Effectively mandatory" was defined as being necessary for promotion or advancement purposes.
} 
Several discussions were undertaken with the team in order to categorize the questions.

We established an online database called Evaluation Central ${ }^{5}$. At this site Evaluation

Managers from each institution are invited to register and to confirm or amend the question typology that was proposed.

There were two distinct groupings of questions: 1) questions about the lecturer and the subject; and 2) questions about the student and their learning. The details of each QT are given below.

\section{QTs relating to the Lecturer and Subject}

\section{Clear Aims:}

This refers to the clarity of the aims of the class or subject or course in terms of standards and objectives, not the clarity of the lecturer or the teaching (the latter is captured under "Clear Explanations").

For example: "The subject objectives were made clear to me".

\section{Clear Explanations:}

This captures the clarity of the lecturer in giving explanations either a) in general terms, or b) in outlining expectations of the course.

For example: "The lecturer was able to communicate concepts clearly”.

\section{Organised:}

This refers to the extent to which either the lecturer or the subject or unit was well-organised, well-prepared and well-structured

For example: "The teaching of this unit is well-organised".

\section{Motivation/Enthusiasm of Lecturer:}

This refers to the level of teacher's enthusiasm in teaching.

For example: "The lecturer was enthusiastic about the subject”.

\section{Respect:}

This refers to the lecturer's sensitivity to students' problems, politeness and friendliness to students and their cultural backgrounds and/or their different views and opinions.

For example: “The lecturer was sensitive to students' cultural backgrounds”.

\section{Access:}

This refers to the extent to which lecturers were available for consultation outside normal lecturing times.

For example: "The lecturer was available to answer students' inquiries".

\section{Teacher knowledge:}

This refers to the perceived understanding by students of the lecturers' knowledge of the content/subject matter that he or she was teaching.

For example: "The lecturer has a sound knowledge of the topic".

8. Overall Teaching Quality

This captures the overall teaching quality of the lecturer.

For example: "This teacher communicates effectively with students/This subject is well-taught”.

\section{QTs related to the Student and their Learning}

\section{Motivation/Enthusiasm of Student:}

This refers to the level of student motivation and enthusiasm.

For example: "I am motivated to achieve learning outcomes".

\section{Student knowledge:}

\footnotetext{
${ }^{5}$ The address for this website is http://tlu.ecom.unimelb.edu.au/evaluationcentral
} 
This refers to whether the students felt that - as a result of the lecturer's classes - they had gained an understanding of the subject matter.

For example: "In this teacher's class I have gained a good understanding of the concepts covered". 


\section{Stimulating/Interesting/Motivating:}

This refers to the level of interest generated on the part of the student from the classes. Did the lecturer inspire the students? Motivate them? Get them to think, Challenge them?

For example: "The teaching staff motivated me to do my best work".

\section{Gave Feedback:}

This refers to whether the lecturer made time to assist students with the learning needs and problems.

For example: "The feedback on my work is provided promptly".

\section{Assessment:}

This refers to the nature and effectiveness and clarity of the assessment tasks requested by lecturers in assessing students' understanding of the subject content.

For example: "Overall the assessment in this unit is fair".

\section{Students' Needs and Learning Skills:}

This refers to whether lecturers were sensitive to students learning needs and to the extent to which the lecturer actively developed learning skills (critical thinking, discursive knowledge, understanding rather than memorizing, etc).

For example: "My learning in this subject was well supported".

\section{Receives Feedback:}

This captures the extent to which student feedback was encouraged and whether the feedback was used to improve teaching.

For example: “The teacher shows genuine interest in improving his/her teaching”.

\section{Teaching Methods/Material/Aids Used:}

This refers to the students' perception of teaching aids and methods used for teaching. Were they useful, effective, relevant?

For example: "The teacher related the course materials to real life situations". "I found the teaching methods used in this subject were effective in helping me to learn".

\section{Workload:}

This refers to the workload expected. Was it commensurate with expectations, fair or unreasonable?

For example: "The workload was appropriate for a subject at this level”.

\section{Overall Effectiveness:}

This is an overall judgement by the students on the lecturer's effectiveness and/or the effectiveness of the unit or subject taught.

For example: "Overall how would you rate the learning experience in this course".

\section{Miscellaneous:}

This is for questions, open comment, etc., that does not naturally fit the other categories.

For example: "Work marked by this teacher is returned in a reasonable time".

\section{A Descriptive Analysis of Surveys Used by Institutions}

In 1998 the Graduate Careers Council of Australian (GCCA 1999) undertook the Institutional Arrangements for Student Feedback (IASF) project. One of the purposes was to prepare an inventory of instruments used by universities to survey students and to prepare an analysis of common elements. It was concluded that: “... in the teaching and learning area, for example, often they are the same surveys or are modifications from the same two or three originals ..." (pg. 14, GCCA 1999). However, Barrie and Ginns (2007, pg. 278) claim that: “...each university develops its surveys in isolation". 
In this section we examine the surveys to determine if their form is influenced by the institution. This is based on two analyses. The first uses the proportion of all question types that are student oriented to determine if there are patterns by the group to which the university belongs. In the second part of this section we report on the results of a cluster analysis of institutions by type of survey they use.

\subsection{The Classification by Focus on Student Learning}

The schema developed in Section 2 contains two distinct groupings defined by questions about the lecturer and subject and questions about the student and learning. For the QTS of each institution the student learning quotient (SLQ) is defined as:

$$
S L Q=\left(\frac{\text { number of student and learning type questions }}{\text { number of total question types used }}\right) \times 100
$$

These are reported in Table 1 by the groupings of each university and the institutions within each grouping are ordered by their $S L Q$. The average across all universities in our set is $S L Q$ $=55.8$ which indicates that there is a slightly higher proportion of student and learning QTs.

From Table 1 we note that the university with the greatest ratio of student and learning questions in their QTS is the University of Wollongong whereas the University of Tasmania and Southern Cross University both have the greatest ratio of lecturer and subject questions. Within each grouping of institutions there is a range of SLQ values. We consider five groupings of Australian Universities defined as: The Group of Eight (GO8), The Australian Technology Network (ATN), The Innovative Research Universities (IRU), The New Generation Universities (NGU) and we refer to the remaining institutions as Independents $(I N D)^{6}$. Interestingly all of the $A T N$ institutions have surveys with a higher $S L Q$ than average, while except for Griffith University, all of the IRU institutions have $S L Q$ s less than average. This suggests that the technology- oriented institutions give more emphasis to the student learning type questions while the Innovative Research Universities focus their surveys more

\footnotetext{
${ }^{6}$ An overview of these groupings is available on the Australian Education Network site at www.australianuniversities.com.
} 
on lecturer and subject characteristics. All the other groupings of institutions demonstrate no particular pattern in their SLQs.

Insert Table 1 here

\subsection{A Cluster Analysis of the Universities}

We apply an agglomeration cluster analysis where the similarity measure we use is defined as the number of questions of the same type that each university's survey used based on the schema developed in Section 2 (See Russell \& Rao, 1940). ${ }^{7}$ Using the furthest neighbor measure between clusters we clustered the universities into groups described by the dendrogram in Figure $1 .^{8}$ In the far left of the figure each institution is in a cluster with only one member. The closest universities are combined first then the next progressively until there is only one cluster. The dissimilarity between the members of the cluster is given by the length of the horizontal line to the point where they join.

The clustering process can be stopped once a specific number of clusters have been formed. For example, the membership of those clusters defined when there are 5 clusters is given in Figure 1 where each cluster group is identified in Column C-5. From Figure 1 we note that for the case of 5 clusters the largest group of similar surveys is composed of 17 universities. Aside from defining groups, cluster analysis can also identify “outliers”, in this case we find that La Trobe University alone defines one of the five clusters. From Figure 1 we can also identify the membership in the 12 clusters as shown by column C-12. Those universities identified as "outliers" in Figure 1 - might investigate whether they should include information that other universities are using in their measurement of teaching effectiveness.

From Figure 1 we can determine if the cluster definitions coincide with the groupings of Australian institutions as defined in Table 1. Three GO8 universities (ANU, Sydney, and

\footnotetext{
7 See Appendix B in Davies et al. (2007).

${ }^{8}$ More detail as to the process by which the agglomeration cluster method operates can be found in Kaufman and Rousseeuw (1990).
} 
NSW) are all included in cluster C-12,1, with three additional GO8s (Queensland, W

Australia, and Adelaide) in cluster C-12,7. Only two Victorian institutions (Monash and Melbourne) are in separate clusters. We also note that four members of the NGU (Canberra, S

Queensland, W Sydney and Edith Cowan) are clustered in C-5,3. Of the NGU only Ballarat is in a different cluster. Thus we observe a correspondence between the group definitions for GO8 and NGU institutions and the clusters to which they are allocated.

Insert Figure 1 here

In order to identify the characteristics of each cluster we construct a typical survey by cluster in Table 2. This was done by noting which QTs have more than $50 \%$ of the cluster members use them in their survey with a marker $(\bullet)$. From Table 2 we note that the largest cluster in the 5 cluster set (\#2) has the largest number of QTs and that most of the smaller clusters have surveys that use fewer number of QTs. We also note that there are some QTs that are employed much more widely than others. In the next section we investigate the relationship between the QTs used on each survey as defined by our schema developed in Section 2 and their frequency of use.

\section{Insert Table 2 here}

\section{An Analysis of Questions by Type.}

In this section we first investigate the differences by the institution's membership in different groups and then we perform a cluster analysis to establish the similarity between the pattern of question type used across institutions.

\subsection{Question Type Usage by Institutional Grouping}

By considering the five groupings of Australian universities defined in Table 1 we examine the tendency for certain groups to employ particular QTs more than others. Because membership in these groups is based on similarities in scale and focus we might expect that this would influence the types of information they request. 
Table 3 reports the proportion of each group that use each QT. The cells in Table 3 are ranked by the frequency of QT use by All Institutions. Both the QTs most likely $(12,18$ and 14) and least likely (17, 10 and 15) to be asked fall into our category of QTs about the student and their learning. QTs 1 and 2 are the most likely questions to be asked that fall into our category of QTs about the lecturer and subject. There are also some distinct patterns of QTs that seem to follow institutional patterns. Within the groupings of the Universities all members of the G08 ask QTs 14 and 11, all members of the ATN ask QTs 12 and 18 and all members of the NGU ask QT 18 . However, there is no one question that is asked by all members of the IRU. In addition many of the members of the ATN ask QTs 9 and 16 which are both QTs that are not commonly asked by All Institutions. In comparison, the G08 members are unlikely to pose QT 1 which is the $5^{\text {th }}$ ranked question by All Institutions and none of the G08 ask QT 13 which is the $9^{\text {th }}$ ranked question by All Institutions. Another interesting aspect of the use of different question types is that those members of the Independent group as well as the members of the ATN are almost twice as likely to include a questions related to teaching methods and materials used (\#16) than the average institution.

Insert Table 3 here

Some of these results are also evident from Table 2 which reports the typical survey by cluster in order to identify the characteristics of each cluster. From this Table we find that QTs 4 to 10 and 15 to 17 are not widely employed while QTs 2, 12, 14, and 18 are more widely used. Also we note that the single institutions that comprise clusters 9 to 12 pose few of the QTs from 5 to 11 and 15 to 17.

\subsection{A Cluster Analysis of the Question Types}

In order to determine the relationship between the various questions asked in the surveys we use a cluster analysis based on frequency that these QTs are employed. A 
similarity matrix to compare QTs is defined by determining the number of universities that pose each type of question. ${ }^{9}$

Using the 18 by 18 similarity matrix of counts of universities that use the same QTs, we apply an agglomeration cluster analysis where the inter-cluster similarity is measured using the complete linkage distance. From Figure 2 we note that if we stop the clustering algorithm when there are six clusters QTs 9 (Motivation/Enthusiasm of Student), 17 (Workload), 10 (Student Knowledge), and 15 (Receives Feedback) are placed in their own cluster. QTs 17, 10 and 15 are the most rarely posed question types. However QT 9 is used by more than a third of the institutions of which the predominant portion are members of the ATN. It is also noteworthy that QTs 1, 8 and 13 although widely used as noted from Table 2, are not included in the largest cluster.

Insert Figure 2 here

\section{Conclusions}

National quality assurance surveys that gather data from graduates on their experiences of their entire course of study are used in a number of countries including Australia. However, to gain an understanding of student perceptions of individual lecturers and units of study institution-specific surveys are often used. In this paper we have examined the QTS used by Australian Universities. We have attempted to categorize the questions used in these surveys so we can determine if the form of the questionnaires can be used to identify how different universities approach the measurement of teaching effectiveness by their academic staff.

We explored how different universities were similar to each other based on which questions were used. In order to establish these groupings we employed a cluster analysis to provide groupings of universities based on the types of questions they include in their QTS. The result of this analysis found that some universities use a QTS that is quite distinct from the majority of other institutions. This is important information for Universities and could be used by them to inform any redesign of their internal QTS. If particular institutions wish to

\footnotetext{
${ }^{9}$ Appendix B in Davies et al (2007) lists the entire table of proximities.
} 
bench mark against others with whom they wish to align themselves a review of the questions they use in the QTS would appear to be in order. We found that all members of the GO8 ask question types 14 and 11, all members of the ATN ask question types 12 and 18 and all members of the NGU ask question type 18. We also found that the ATN institutions ask a higher percentage of student learning questions than average and that practically all the IRU institutions ask fewer than average. From our cluster analysis we observe a correspondence between the group definitions for GO8 and NGU institutions and the clusters to which they are allocated.

Besides the analysis by university of the QTS, we also investigated if there was a pattern to the particular types of questions that are used in these surveys. To accomplish this we defined a matrix of similarity between the question types as defined by our classification and based on the number of universities that asked the same questions. The outcome of this analysis reveals that questions relating to increases in student knowledge, the degree to which the student's feedback to the instructor is encouraged or not, and the expectation of workload $(10,15$, and 17$)$ were not commonly included in the types of questions asked. Whereas, questions concerning Feedback, General Effectiveness, and Student's Needs and Learning Skills $(12,18$, and 14) are far more likely to be included in the survey.

Even though a form of QTS is used in almost all Australian universities we find that the surveys vary from institution to institution. Based on the survey results and the analysis conducted it is anticipated that Australian institutions can be better informed as to how their QTS compares to the surveys conducted by other tertiary institutions and can consider adjusting their QTS based on the analysis conducted here.

\section{Notes on contributors}

Joe Hirschberg is an Associate Professor in the Department of Economics at the University of Melbourne. He has more than 20 years experience teaching in both US and Australian Universities. In addition, he has published widely in the areas of applied and theoretical 
econometrics and statistics. His experience in applied econometrics includes an analysis of tertiary education. He is the recipient of large grants to examine the Quantitative Analysis of the Student Learning Experience.

Jenny Lye holds the rank of Reader/Associate Professor in the Department of Economics at the University of Melbourne. She has an extensive international publication record in the areas of theoretical and applied econometrics and statistics. Her recent research includes a series of publications in the statistical analysis of issues in tertiary education. She is the recipient of large grants to examine the Quantitative Analysis of the Student Learning Experience.

Carol Johnston is the Assistant Dean (Special Projects Research) and an Associate Professor in the Faculty of Economics and Commerce at the University of Melbourne. She is the former Director of the Teaching and Learning Unit for the Faculty of Economics and Commerce at the University of Melbourne. She is a recipient of many teaching and learning grants. She has extensive project leadership experience and experience in evaluating teaching and learning performance.

Martin Davies is a Senior Lecturer and Honorary Research Fellow in Teaching and Learning Unit of the Economics and Commerce Faculty at the University of Melbourne. He has a detailed understanding of teaching and learning issues relevant to the tertiary sector. He has published widely in a range of education, cognitive science, political science and philosophy journals. He has also coordinated a number of Quantitative Teaching and Learning Forums.

\section{References}

Barrie, S., and P. Ginns. 2007. The Linking of National Teaching Performance Indicators to Improvements in Teaching and Learning in Classrooms. Quality in Higher Education, 13: 275-286. 
Davies, M., J. Hirschberg, C. Johnston, and J. Lye. 2007. An Analysis of the Questions on University Teaching Surveys and the Universities that Use Them: the Australian Experience. Department of Economics, University of Melbourne, Working Paper, No 994.

DEST 2006. Learning and Performance Fund 2006 Administrative Information for Providers, available online at: http://tinyurl.com/2ygzxg (accessed $12^{\text {th }}$ November 2007).

GCCA1999. Institutional Arrangements for Student Feedback Project Report. A report of the investigation into university practices for obtaining student feedback. Parkville, Victoria: Graduate Careers Council of Australia ltd.

Jackson, D. L., C. R. Teal, S. J. Raines, T. R. Nansel, C. S. Burdsal, and R. C. Force. 1999. The Dimensions of Students' Perceptions of Teaching Effectiveness. Educational and Psychological Measurement; 59: 580-96.

Kaufman, L., and P. J. Rousseeuw. 1990. Finding Groups in Data. New York: John Wiley \& Sons.

Lizzio, A., K. Wilson, and R. Simons. 2002. University student's perceptions of the learning environment and academic outcomes: Implications for theory and practice. Studies in Higher Education, 27: 27-52.

Ramsden, P. 1991a. A Performance Indicator of Teaching Quality in Higher Education: the Course Experience Questionnaire. Studies in Higher Education, 16: 129-150.

Ramsden, P. 1991b. Report on the CEQ Trial. in R. Linke (Ed.), Performance Indicators in Higher Education (Vol. 2). Canberra: Australian Government Publishing Service.

Ramsden, P. 2003. Learning to Teach in Higher Education. New York: RoutledgeFalmer, Second Edition.

Ramsden, P., and N. Entwistle. 1981. Effects of academic departments on students' approaches to studying. British Journal of Educational Psychology, 51: 368-383.

Russell, P. and T. Rao. 1940. On habitat and association of species of anopheline larvae in South-Eastern Madras. Journal of the Malaria Institute of India, 3: 153-178. 
Table 1: A Comparison of $S L Q$ by Institution

\begin{tabular}{|ll|ll|}
\hline \multicolumn{1}{|c|}{ Institution } & SLQ & Institution & SLQ \\
Group of Eight (GO8) & & New Generation Universities (NGU) & \\
The University of Melbourne & 71 & Victoria University & 67 \\
The University of New South Wales & 67 & University of Ballarat & 63 \\
The University of Sydney & 67 & Central Queensland University & 56 \\
The Australian National University & 57 & Edith Cowan University & 56 \\
The University of Adelaide & 50 & University of Western Sydney & 53 \\
The University of Western Australia & 44 & University of the Sunshine Coast & 50 \\
The University of Queensland & 40 & University of Canberra & 50 \\
Monash University & 36 & University of Southern Queensland & 38 \\
Innovative Research Universities (IRU) & & Southern Cross University & 33 \\
Griffith University & 78 & Independents (IND) & \\
La Trobe University & 50 & University of Wollongong & 83 \\
Macquarie University & 50 & Deakin University & 75 \\
The University of Newcastle & 50 & Charles Sturt University & 67 \\
The Flinders University of South Australia & 40 & Swinburne University of Technology & 60 \\
Murdoch University & 36 & Charles Darwin University & 57 \\
Australian Technology Network (ATN) & & James Cook University & 50 \\
Curtin University of Technology & 78 & The University of New England & 45 \\
Queensland University of Technology & 78 & University of Tasmania & 33 \\
University of South Australia & 63 & & \\
University of Technology, Sydney & 63 & & \\
Royal Melbourne Institute of Technology & 57 & & \\
\hline
\end{tabular}

Table 2. Typical Surveys by Cluster Sets

\begin{tabular}{|c|c|c|c|}
\hline \multirow{2}{*}{ Question Types (QTs) } & \multicolumn{2}{|c|}{\begin{tabular}{|c|}
12 Clusters \\
\end{tabular}} & \multirow{2}{*}{ 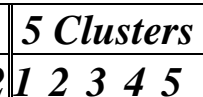 } \\
\hline & \begin{tabular}{l|llllllll}
1 & 2 & 3 & 4 & 5 & 6 & 7 & 8 & 9
\end{tabular} & 101112 & \\
\hline 1 Clear Aims & $\bullet \bullet \bullet \bullet \bullet \bullet \bullet$ & $\bullet \bullet$ & $\bullet \bullet \bullet$ \\
\hline 2 Clear Explanations & & & \\
\hline 3 Organised & $\bullet \bullet$ & • & $\bullet \bullet$ \\
\hline 4 Motivation/Enthusiasm of Lecturer & $\bullet \bullet \bullet$ & $\bullet$ & $\bullet$ \\
\hline 5 Respect & $\bullet$ & & \\
\hline 6 Access & $\bullet \bullet \bullet$ & & $\bullet$ \\
\hline 7 Teacher Knowledge & $\bullet$ & - & | \\
\hline 8 Overall Teaching Quality & $\bullet \bullet \bullet \bullet$ & & $\bullet$ \\
\hline 9 Motivation/Enthusiasm of Student & $\bullet \bullet$ & $\bullet$ & \\
\hline 10Student Knowledge & & 0 & \\
\hline 11 Stimulating/Interesting/Motivating & $\bullet \bullet \bullet$ & & $\bullet \bullet$ \\
\hline 12 Gave Feedback & & & 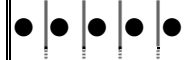 \\
\hline 13Assessment & $\bullet$ & $\bullet$ & $\bullet$ \\
\hline 14Students Needs and learning Skills & $\bullet \bullet \bullet \bullet$ & $\bullet$ & $\bullet \bullet \bullet \bullet$ \\
\hline 15Receives Feedback & $\bullet$ & & \\
\hline 16 Teaching Method/Material/Aids used & $\cdot \cdot$ & & \\
\hline 17 Workload & $\bullet$ & & \\
\hline 18Overall effectiveness & 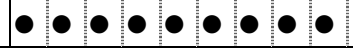 & - & \\
\hline
\end{tabular}


Table 3: The percentage of each group that uses each QT, ranked by frequency of all institutions use of the questions.

\begin{tabular}{|l|l|lllll|l|}
\hline \multicolumn{2}{|l|}{ Question type (QT) } & G08 & ATN & IRU & NGU & IND & AII \\
\hline $\mathbf{1 2}$ & Gave Feedback & 75 & 100 & 83 & 78 & 88 & 84 \\
$\mathbf{1 8}$ & Overall effectiveness & 88 & 100 & 67 & 100 & 63 & 82 \\
$\mathbf{1 4}$ & Students Needs and learning Skills & 100 & 60 & 67 & 78 & 75 & 79 \\
$\mathbf{2}$ & Clear Explanations & 88 & 60 & 83 & 78 & 38 & 71 \\
$\mathbf{1}$ & Clear Aims & 38 & 80 & 50 & 89 & 63 & 66 \\
$\mathbf{1 1}$ & Stimulating/Interesting/Motivating & 100 & 60 & 33 & 56 & 75 & 66 \\
$\mathbf{3}$ & Organised & 75 & 20 & 67 & 56 & 50 & 58 \\
$\mathbf{8}$ & Overall Teaching Quality & 38 & 40 & 33 & 44 & 75 & 50 \\
$\mathbf{1 3}$ & Assessment & 0 & 60 & 50 & 56 & 63 & 47 \\
$\mathbf{6}$ & Access & 38 & 20 & 50 & 44 & 50 & 45 \\
$\mathbf{4}$ & Motivation/Enthusiasm of Lecturer & 50 & 20 & 50 & 44 & 25 & 40 \\
$\mathbf{7}$ & Teacher Knowledge & 25 & 20 & 17 & 56 & 50 & 37 \\
$\mathbf{9}$ & Motivation/Enthusiasm of Student & 25 & 80 & 17 & 33 & 38 & 34 \\
$\mathbf{1 6}$ & Teaching Method/Material/Aids used & 25 & 60 & 17 & 22 & 63 & 34 \\
$\mathbf{5}$ & Respect & 38 & 0 & 33 & 22 & 25 & 26 \\
$\mathbf{1 7}$ & Workload & 13 & 20 & 17 & 11 & 13 & 16 \\
$\mathbf{1 0}$ & Student Knowledge & 0 & 0 & 17 & 11 & 25 & 11 \\
$\mathbf{1 5}$ & Receives Feedback & 0 & 20 & 17 & 33 & 0 & 11 \\
\hline
\end{tabular}




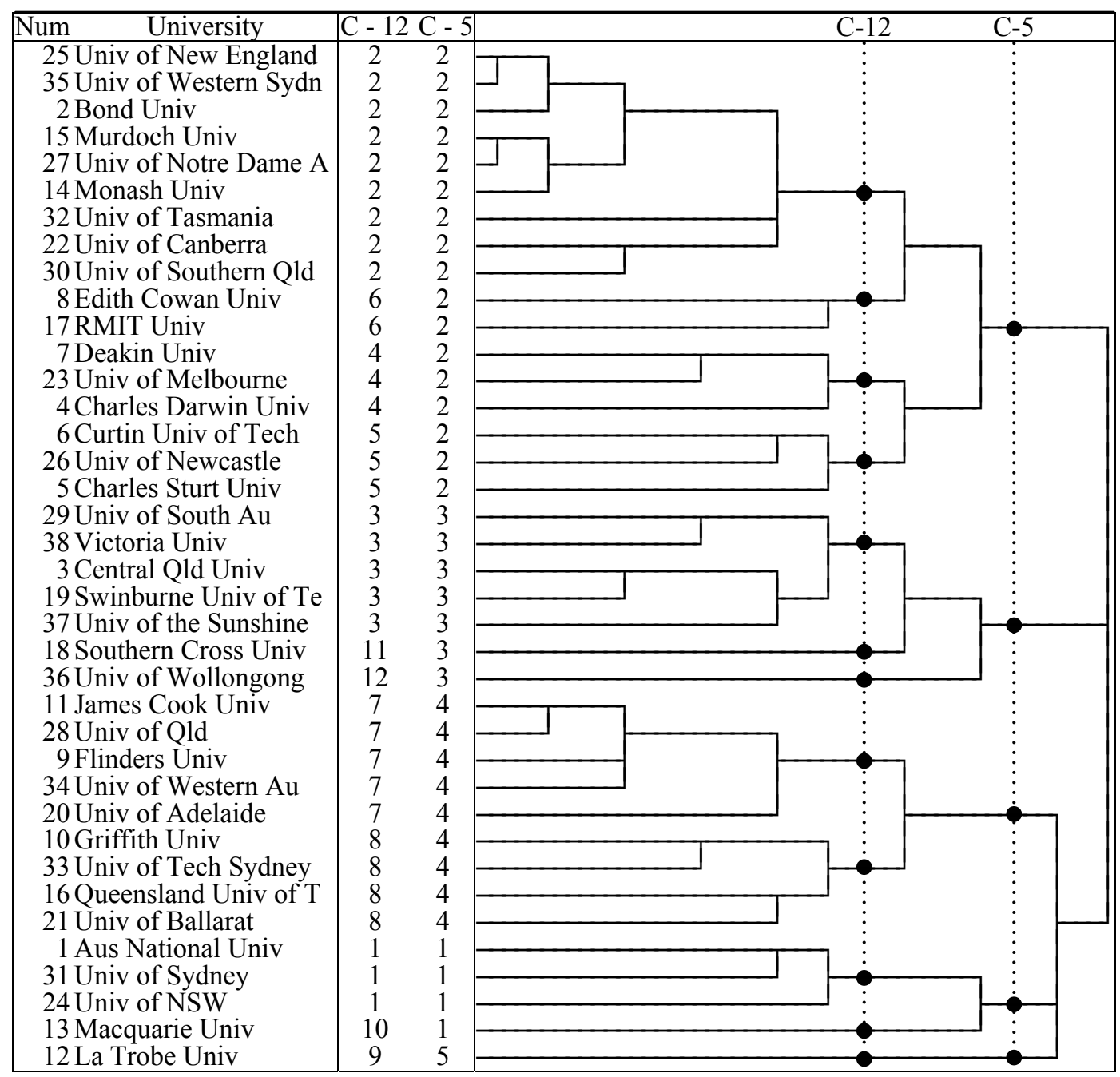

Figure 1. The Dendrogram of the hierarchical cluster analysis of Australian universities created using a complete linkage method. The $\mathrm{C}-5$ and $\mathrm{C}-12$ columns indicate the membership in the 5 and 12 cluster cases. 


\begin{tabular}{|l|l|l|}
\hline \multicolumn{1}{|c|}{ Question Type (QT) } & Cluster & \\
\hline 14Students Needs and learning Skills & 2 & 2 \\
18Overall effectiveness & 2 &
\end{tabular}

Figure 2. The Dendrogram of the Hierarchical Cluster Analysis of the QTS questions based on a complete (or furthest neighbour) linkage method. 